Article

\title{
Cellulose Nanofibril (CNF) Films and Xylan from Hot Water Extracted Birch Kraft Pulps
}

\author{
Marc Borrega * and Hannes Orelma \\ VTT Technical Research Centre of Finland Ltd., Tietotie 2, FI-02150 Espoo, Finland \\ * Correspondence: marc.borrega@vtt.fi; Tel.: +358-4048-20837
}

Received: 26 July 2019; Accepted: 16 August 2019; Published: 20 August 2019

check for updates

Featured Application: Hot water extraction of bleached kraft pulp can be used to produce cellulose nanofibril (CNF) films with improved barrier properties for food packaging and to recover low molar mass xylan for high-value applications (e.g., prebiotics).

\begin{abstract}
The effects of xylan extraction from birch kraft pulp on the manufacture and properties of cellulose nanofibril (CNF) films were here investigated. Hot water extractions of bleached and unbleached kraft pulps were performed in a flow-through system to remove and recover the xylan. After the extraction, the pulps were oxidized with 2,2,6,6-tetramethylpiperidine-1-oxyl radical (TEMPO) and fibrillated in a high-pressure microfluidizer. Compared to CNF from bleached kraft pulp, the CNF dispersions obtained from water-extracted pulps were less viscous and generally contained a higher amount of microfiber fragments, although smaller in size. In all cases, however, smooth and highly transparent films were produced from the CNF dispersions after the addition of sorbitol as plasticizer. The CNF films made from water-extracted pulps showed a lower tensile strength and ductility, probably due to their lower xylan content, but the stiffness was only reduced by the presence of lignin. Interestingly, the CNF films from water-extracted bleached pulps were less hydrophilic, and their water vapour permeability was reduced up to $25 \%$. Therefore, hot water extraction of bleached birch kraft pulp could be used to produce CNF films with improved barrier properties for food packaging, while obtaining a high-purity xylan stream for other high-value applications.
\end{abstract}

Keywords: barrier properties; CNF film; hot water extraction; nanocellulose; xylan

\section{Introduction}

Cellulose nanomaterials, which include cellulose nanofibrils (CNF), cellulose nanocrystals (CNC), and bacterial cellulose (BC), are a relatively new family of cellulosic materials with at least one dimension in the nanometre scale [1]. Both CNF and CNC are obtained from wood and plants, but CNF are prepared by mechanical fibrillation of chemical pulps (often after a suitable pre-treatment), and CNC are prepared by acid hydrolysis of highly purified cellulosic substrates (i.e., cotton, microcrystalline cellulose, filter paper). BC, on the other hand, is secreted extracellularly by various bacterial strains, most notably from the Gluconacetobacter genus [1,2]. The mechanical, hydrophilic and rheological properties of cellulose nanomaterials can be exploited in a wide variety of end-uses such as paper-making, composites, films, aerogels, foams, and food systems [1-6], but owing to their different origin and production process, the three types of nanocelluloses (i.e., CNF, CNC, $\mathrm{BC}$ ) present unique structural features and properties.

Currently, many research efforts are being directed towards the development of CNF films to replace oil-based plastics in packaging applications. Since cellulose-based films are rather brittle, the addition of plasticizers is often required to reach the desired workability and performance. Sorbitol is one of the most extensively used natural plasticizers and a promising candidate to replace 
synthetic plasticizers in industrial operations [7]. Nonetheless, the main limitation for the industrial production of CNF films has traditionally been the high energy consumption required for the mechanical delamination of pulp fibres, as several passes (5-20) through a high-pressure homogenizer or similar device are often required to reach a sufficient degree of fibrillation [8-10]. The energy consumption, however, can be reduced by applying enzymatic or chemical pre-treatments to the cellulosic pulps. Enzymes are used to decrease the extent of hydrogen bonding by selectively hydrolysing amorphous cellulose and other polysaccharides in the fibres, while chemical pre-treatments are used to add ionic charge and promote the swelling, repulsion and separation of individual fibrils $[3,11,12]$. Chemical oxidation by 2,2,6,6-tetramethylpiperidine-1-oxyl radical (TEMPO) is the most common pre-treatment applied. The TEMPO-mediated oxidation increases the reactivity of cellulose fibres towards fibrillation by selectively converting the $\mathrm{C} 6$ in the glucose units into carboxylate groups, thus creating electrostatic forces that aid the separation of the fibrils [13]. After TEMPO pre-treatment, the cellulosic pulps only need a few passes to obtain CNF of 4-20 nm in width, and films made from these fibrils are transparent, flexible and have high tensile strength [13]. Several forest companies (e.g., Borregaard, American Process, Stora Enso, UPM-Kymmene, Sappi, Nippon Paper) are now producing CNF at a pilot or industrial scale, and other producers are expected to join this rapidly growing market in the near future.

Bleached chemical pulps used for the manufacture of graphic paper are typically selected for the preparation of $\mathrm{CNF}$, which means that the lignin content in the pulps is negligible $(<1 \%)$ but the hemicellulosic content varies between $15-30 \%$, depending on the botanical origin of the wood material. The hemicelluloses appear to facilitate the swelling and mechanical delamination of pulp fibres $[14,15]$. However, the presence of xylan in hardwood pulps may limit the accessibility of TEMPO to cellulose during the chemical pre-treatment and thus reduce the extent of cellulose oxidation reached [16,17]. Moreover, TEMPO-oxidation removes substantial amounts of xylan from the pulp [17], so the potential benefits of xylan towards fibre swelling and fibrillation are at least partially lost. Due to their hydrophilic nature, the presence of hemicelluloses in the pulp and in the resulting CNF may also be detrimental for the production of films in which moisture barrier properties are required [18]. In unbleached chemical pulps, the presence of residual lignin (up to 15\%) has also been reported to enhance the deconstruction of the cell wall during mechanical fibrillation $[19,20]$.

Previous studies have investigated the effects of extracting hemicelluloses from the pulp on the preparation of CNF and on the properties of the films made thereof [14-18,21,22]. From a biorefinery point of view, the extraction of hemicelluloses should also be accompanied by their recovery and subsequent utilization in high-value applications. Hemicelluloses can be utilized in the manufacture of films, fuels, chemicals, food additives, hydrocolloids, nutraceuticals, etc [23,24]. Their utilization potential comes mainly determined by the purity, molar mass and degree of substitution. In recent years, several strategies to recover the hemicelluloses from pulp have been investigated using alkali $[25,26]$, ionic liquids [27], and hydrothermal treatments [28,29]. Among those, the hydrothermal treatment offers the obvious advantage of being an environmentally friendly process, as water is the only solvent used. Up to $80 \%$ of the xylan in unbleached birch kraft pulp can be extracted during a hot water treatment in a flow-through reactor, with an average molar mass between 5-10 kDa depending on the flow rate [29]. The cellulose yield after the treatment remains largely unaffected, but the degree of polymerization (DP) of the cellulose fraction is considerably reduced. This decrease in cellulose DP should not be an impediment for the effective fibrillation of the water-extracted pulp, as cellulosic materials with low DP values have been successfully converted into homogeneous CNF networks by mechanical processing [8]. Moreover, chemical pre-treatment of pulp with TEMPO is also known to promote significant depolymerisation of cellulose [13].

In this study, hot water extractions of bleached and unbleached birch kraft pulp were conducted in a flow-through system to partially remove and recover the xylan, and to produce pulps with varying chemical composition. The xylan fractions in the aqueous hydrolysates were characterized in terms of purity and molar mass to assess potential applications. The water-extracted pulps were then subjected 
to TEMPO-mediated oxidation for the preparation of CNF, and the resulting CNF dispersions were used to make films. The effects of xylan removal on the preparation and quality of the CNF as well as on the properties of the CNF films are discussed.

\section{Materials and Methods}

\subsection{Pulp Material and Hot Water Extractions}

Bleached and unbleached birch (Betula spp.) kraft pulps were delivered from a pulp mill in Finland. The bleached pulp was delivered as dry sheets, while the unbleached pulp was delivered wet after taking it from the production line before the oxygen delignification stage. Prior to the hot water extractions, the bleached pulp sheets were manually disintegrated, and the unbleached pulp was washed with water and screened through a table-top plate screener $(0.35 \mathrm{~mm}$ mesh) to remove the pulping rejects. Hot water extractions of pulp ( $25 \mathrm{~g}$ dry mass) were conducted in a $190 \mathrm{~mL}$ flow-through percolation reactor (Unipress Equipment, Warsaw, Poland) equipped with a high-pressure pump, preheater and electric heating jackets, heat exchanger, and back-pressure regulator. The extraction temperature was $240{ }^{\circ} \mathrm{C}$, the extraction time was 2 or $10 \mathrm{~min}$, and the flow rate was $400 \mathrm{~mL} / \mathrm{min}$ (the flow was not re-circulated). The process conditions were selected based on the results from Borrega et al. [28]. The aqueous hydrolysate exiting the reactor during the extraction experiments was immediately cooled by the heat exchanger and collected in a sampling container. The extracted pulp was thoroughly washed with tap water and stored for further processing and analyses. Each experiment was repeated 4-5 times. More information on the operational equipment and procedure can be found elsewhere $[28,29]$.

\subsection{Chemical and Molecular Analyses of Pulps and Hydrolysates}

The carbohydrate and lignin content of the pulps, before and after the hot water extractions, were determined after a two-stage acid hydrolysis, according to the analytical method NREL/TP-510-42618 issued by the US National Renewable Laboratory (NREL). Neutral monosaccharides were determined by high-performance anion exchange chromatography with pulse amperometric detection (HPAEC-PAD) in a Dionex ICS-3000 (Thermo Fisher Scientific, Sunnyvale, CA, USA) system. Based on the amount of neutral monosaccharides, the cellulose, xylan and glucomannan fractions in the pulps were calculated using the Janson's formulas [30]. With these formulas, cellulose is defined as the content of anhydroglucose in the sample after subtracting the contribution of glucose to glucomannan, and xylan is defined as the content of anhydroxylose with uronic acid substituents. The amount of acid insoluble (Klason) lignin was quantified gravimetrically, and the amount of acid soluble lignin (ASL) was determined in a Shimadzu (Kyoto, Japan) UV-2550 spectrophotometer at a wavelength of $205 \mathrm{~nm}$, using an adsorption coefficient of $110 \mathrm{~L} /(\mathrm{g} \cdot \mathrm{cm})$. The carboxylate content of the pulps before and after TEMPO-mediated oxidation was determined according to the SCAN-CM 65:02 method.

The intrinsic viscosity of the pulps was determined in cupriethylenediamine (CED) according to the SCAN-CM 15:99 method. The molar mass distribution (MMD) of the pulps was obtained by size exclusion chromatography (SEC) using $2 \times$ PL gel MiniMixed A columns with a pre-column in $0.8 \%$ $\mathrm{LiCl} / \mathrm{DMAc}$ as eluent $\left(0.36 \mathrm{~mL} / \mathrm{min}, \mathrm{T}=80^{\circ} \mathrm{C}\right)$. The elution curves were detected using a Waters 2414 Refractive index detector, and the MMD was calculated against eight pullulan standards (6.1-624 kDa), using Waters Empower 3 software.

The total number of monosaccharides in the hydrolysates was quantified by HPAEC-PAD after total hydrolysis in an autoclave at $121^{\circ} \mathrm{C}$ for $60 \mathrm{~min}$, according to the analytical method NREL/TP-510-42623 issued by the US NREL. The molar mass of dissolved compounds was determined SEC in a PSS (Mainz, Germany) instrument. Prior to the analyses, the samples were dissolved overnight in $1 \mathrm{M} \mathrm{NaOH}$ and filtered through $0.45 \mu \mathrm{m}$ filters. The SEC measurements were performed in $0.1 \mathrm{M} \mathrm{NaOH}$ as eluent. The MMD of the dissolved compounds was calculated against eight pullulan standards (6.1-624 kDa), using Waters Empower 3 software. 


\subsection{TEMPO Oxidation and Fibrillation of Pulps}

The initial bleached kraft pulp and the water-extracted pulps were oxidized in a TEMPO/NaBr $/ \mathrm{NaClO}$ system prior to their fibrillation. Briefly, the pulps were first suspended in water at $1 \%$ consistency, together with $0.13 \mathrm{mmol}$ of TEMPO and $1.0 \mathrm{mmol}$ of $\mathrm{NaBr}$ per dry gram of pulp. The $\mathrm{pH}$ was adjusted to 10 by addition of $1 \mathrm{M} \mathrm{NaOH}$, and the suspension was stirred for over $1 \mathrm{~h}$ to allow swelling of the pulp. The TEMPO-mediated oxidation was then conducted by gradually adding amounts of $\mathrm{NaClO}$ (total amount was $2.5 \mathrm{mmol}$ per dry gram of pulp) while maintaining the $\mathrm{pH}$ at 10 by addition of $\mathrm{NaOH}$. Once the $\mathrm{pH}$ remained constant (i.e., no consumption of $\mathrm{NaOH}$ ), the pulps were filtered through nylon filter bags and then washed. To facilitate the washing, the pulps were acidified by re-diluting in water and adjusting the $\mathrm{pH}$ to $2.5-3$ by addition of $1 \mathrm{M} \mathrm{HCl}$. Thereafter, the pulps were washed three times with water.

Mechanical fibrillation of the TEMPO-oxidized pulps was performed in a high-pressure fluidizer (Microfluidizer EH110, Microfluidicies Corp, Westwood, MA, USA) after diluting in water to 1.5\% consistency and adjusting the $\mathrm{pH}$ to neutral. The water-extracted pulps were first homogenized by passing through a $400 \mu \mathrm{m}$ chamber. Subsequently, all the pulps (i.e., kraft pulp and water-extracted pulps) were passed twice through a $200 \mu \mathrm{m}$ chamber and once through a $100 \mu \mathrm{m}$ chamber. The higher viscosity of the CNF dispersion from kraft pulp made the fluidization at $1.5 \%$ consistency rather difficult, particularly during the last pass through the $100 \mu \mathrm{m}$ chamber. Although the consistency of such CNF should have been lower for practical purposes, in this study it was not adjusted to allow for direct comparison with the other CNF samples. After fibrillation, the resulting CNF dispersions were stored in a refrigerator at $4{ }^{\circ} \mathrm{C}$ until further use. Microbial contamination during storage was not observed.

\subsection{Preparation of CNF Films}

The CNF samples were re-dispersed in water to reach a $0.7-1.2 \%$ consistency, and $30 \%(w / w)$ sorbitol was added as plasticizer. The dispersions were pre-homogenized by mixing with a Diaf dissolver for $30 \mathrm{~min}$ at $300 \mathrm{rpm}$, and then with a SpeedMixer (DAC 110.1 VAC-p, Hauschild) for $2 \mathrm{~min}$ at $1500 \mathrm{rpm}$ under vacuum to prevent formation of air bubbles. Next, the dispersions were cast at a line-speed of $1 \mathrm{~m} / \mathrm{min}$ onto a plastic substrate, forming an even and uniform wet layer of 2.0-3.5 mm thickness. Spreading and adhesion between the substrate and the aqueous CNF dispersion was carefully controlled by physical plasma-activation, using a Vetaphone Corona-Plus (Type TF-415, CP1C MKII $2.0 \mathrm{~kW}$, Kolding, Denmark) equipped with an argon/nitrogen plasma unit for increasing the surface energy of the plastic substrate. After drying overnight at ambient conditions, CNF films with thickness of 20-30 $\mu \mathrm{m}$ were delaminated from the plastic support and cut into A4-sized sheets.

\subsection{Microscopic Imaging of CNF by SEM and AFM}

The extent of fibrillation in the CNF samples was investigated by microscopic observation of their micro- and nanofractions. For the microfraction, the CNF samples were diluted 50 times with Milli-Q water and drop-casted on a silicon wafer coated with polyethylenimine (PEI). Images of the samples were obtained with a scanning electron microscope (SEM; Merlin Field Emission (FE)-SEM, Carl Zeiss NTS GmbH, Oberkochen, Germany) after applying a gold-sputter coating ( $30 \mathrm{~mA}, 30 \mathrm{~s})$. The accelerating voltage was kept constant at $3 \mathrm{kV}$ with a grid current of $60 \mathrm{pA}$, and the pixel resolution was $2048 \times 1536$. The dimensions of the microfraction were determined from the SEM micrographs using the open-source image processing software ImageJ 1.51j8. For the nanofraction, the CNF samples were first diluted 10 times in Milli-Q water, sonicated for $10 \mathrm{~min}$ at $25 \%$ amplitude, and centrifuged at 10,400 rpm for $45 \mathrm{~min}$. About $5 \mathrm{~mL}$ of the supernatant were then drop-casted on a PEI-coated silicon wafer. Images of the samples were obtained with an atomic force microscope (AFM; nano-TA scanning probe microscope, Anasys instruments, Santa Barbara, CA, USA). The height imaging was carried out in air with silicon cantilevers operating in tapping mode, with an image size of $5 \times 5 \mu \mathrm{m}^{2}$. From each 
sample, three separate areas were imaged, and no other image processing than flattening was used. The AFM images were processed with Analysis studio software (Anasys instruments).

\subsection{Mechanical Properties of CNF films}

The mechanical properties of the CNF films were determined by tensile testing according to a modified SCAN-P 38:80 method, using a Lloyd LS5 (Lloyd Instruments Ltd., Bognor Regis, UK) tensile testing machine equipped with a $100 \mathrm{~N}$ load cell. The width of the film strips tested was $15 \mathrm{~mm}$, the grip distance was $20 \mathrm{~mm}$, and the testing speed was $2 \mathrm{~mm} / \mathrm{min}$. The thickness of the strips was measured separately for each sample before measurement. The samples were conditioned in a controlled atmosphere $\left(23^{\circ} \mathrm{C}\right.$ and $\left.50 \% \mathrm{RH}\right)$ for at least $24 \mathrm{~h}$ prior to testing. Five strips from each $\mathrm{CNF}$ film were tested.

\subsection{Hygroscopic Properties of CNF Films}

The water sorption isotherms of the CNF films were determined by dynamic vapour sorption (DVS) using a DVS-1 Video (Surface Measurement Systems, London, UK) apparatus. About 2-5 mg of film were placed in the microbalance of the DVS system, and the film was first dried at $25^{\circ} \mathrm{C}$ by lowering the relative humidity (RH) to $0 \%$ with nitrogen gas (flow rate $200 \mathrm{~mL} / \mathrm{min}$ ) until the mass change was lower than $0.002 \mathrm{mg} / \mathrm{min}$ over a $10 \mathrm{~min}$ period. Once dried, the RH in the chamber was increased step-wise to $19,36,54,75$ and $90 \%$ while keeping the temperature at $25^{\circ} \mathrm{C}$. In each step, the RH was kept constant until the mass of the film reached an equilibrium (mass change lower than $0.002 \mathrm{mg} / \mathrm{min}$ over a $10 \mathrm{~min}$ period). A full sorption cycle, including adsorption and desorption, was performed for each sample. Three samples from each CNF film were measured.

\subsection{Water Vapour and Oxygen Transmission of CNF Films}

The water vapour transmission rate of the films was determined gravimetrically by the wet cup method, using a modified ASTM-E-96B procedure. Samples with a test area of $30 \mathrm{~cm}^{2}$ were mounted on circular aluminium cups (68-3000 Vapometer EZ-Cups; Thwing-Albert Instrument Company, West Berlin, NJ, USA) containing distilled water (100\% RH). The films were secured between two neoprene rings to prevent any edge leaks, and an aluminium threaded flanged ring was screwed into the cup to firmly hold the sample. The cups were stored at $23{ }^{\circ} \mathrm{C}$ and $50 \% \mathrm{RH}$ and were weighed periodically until a constant rate of weight reduction was attained. A Climaveneta AXO 10 (Bassano del Grappa, Italy) climate control system was used to control both temperature and humidity conditions in an environmental room. In this test, a 100/50\% RH gradient was used. The humidity gradient is the driving force for water molecules to diffuse within a material. Two samples per film were tested.

Oxygen transmission rates through the films were determined according to the standard ASTM D3985, using the 8001 and 8011 oxygen permeation analysers (Systech Instruments Ltd., Thame, UK). The tests were conducted with $50 \mathrm{~cm}^{2}$ samples at $23^{\circ} \mathrm{C}$ and $0 \%$ or $80 \% \mathrm{RH}$, using $100 \%$ oxygen as a test gas. The films were clamped between the two halves of the testing chamber. Two samples per film were tested.

\section{Results and Discussion}

\subsection{Hot Water Extraction of Pulps}

Bleached and unbleached birch kraft pulps were extracted with water at $240{ }^{\circ} \mathrm{C}$ in a flow-through reactor to partially remove the xylan prior to fibrillation and preparation of CNF films. In the bleached pulp, the xylan content was reduced by $50 \%$ and $75 \%$ after 2 and 10 min of extraction time, respectively (Table 1). In the unbleached pulp, the xylan content was reduced by $70 \%$ after $10 \mathrm{~min}$ of extraction time, and the lignin content remained the same ( $3 \%$ on pulp) even if about $25 \%$ of the lignin in the original unbleached pulp was actually removed. The extraction of xylan came accompanied by a decrease in the anionic charge of the pulp, probably due to the removal of acidic substituents such as 
glucuronic and hexenuronic acid groups [18]. The hot water extractions also promoted minor losses in cellulose yield (less than $10 \%$ ), but the intrinsic viscosity and molar mass in the extracted bleached and unbleached pulps decreased dramatically as a consequence of extensive hydrolytic cleavage of glycosidic bonds in the cellulose fraction $[29,31]$. Under similar extraction conditions $\left(240{ }^{\circ} \mathrm{C}\right.$ for 10 $\mathrm{min}$ ), the viscosity of the unbleached pulp (UBK240.10) was $424 \mathrm{~mL} / \mathrm{g}$, higher than the $165 \mathrm{~mL} / \mathrm{g}$ of the bleached pulp (BBK240.10) (Table 1). The higher viscosity of the UBK240.10 pulp may be related to the higher viscosity of the initial unbleached pulp (UBK), compared to the bleached pulp (BBK), but it is also possible that the residual lignin in the unbleached pulp had a protective effect towards the hydrolytic degradation of cellulose [32].

Table 1. Properties of bleached (BBK) and unbleached kraft (UBK) pulp before and after hot water extractions in a flow-through system (flow rate $400 \mathrm{~mL} / \mathrm{min}$ ).

\begin{tabular}{cccccc}
\hline & BBK & BBK240.2 & BBK240.10 & UBK & UBK240.10 \\
\hline Temperature, ${ }^{\circ} \mathrm{C}$ & - & 240 & 240 & - & 240 \\
Extraction time, min & - & 2 & 10 & - & 10 \\
Pulp yield, \% & - & 86.7 & 74.9 & - & 73.2 \\
Cellulose content, $\%$ & 70.5 & 83.5 & 92.0 & 70.9 & 88.4 \\
Xylan content, \% & 29.1 & 15.9 & 7.5 & 25.7 & 8.2 \\
Glucomannan content, $\%$ & 0.5 & 0.6 & 0.5 & 0.2 & 0.3 \\
Lignin content, $\%$ & - & - & - & 3.1 & 3.2 \\
Anionic charge, mmol/g & 0.05 & 0.01 & $<0.01$ & nd & 0.01 \\
Intrinsic viscosity, mL/g & 738 & 363 & 165 & 1288 & 424 \\
Molar mass (Mw), kDa & nd & 307 & 125 & nd & 380 \\
Polydispersity index & nd & 8.5 & 5.4 & nd & 7.8 \\
\hline
\end{tabular}

The aqueous hydrolysates obtained from the hot water extractions were analysed to assess the recovery of xylan-based compounds. In those hydrolysates obtained from the bleached kraft pulp, the xylose content was $9.5 \%$ and $15.1 \%$ of the initial dry mass of pulp after 2 and 10 min of extraction time, respectively (Table 2). These amounts corresponded to $60-65 \%$ of the total xylan extracted from pulp. In the hydrolysate from the unbleached kraft pulp, the xylose content was $17.4 \%$ of the initial dry mass of pulp, which corresponded to about $88 \%$ of the total xylan extracted. It is likely that xylan losses occurred because some of the xylan was entrapped within the pulp fibres and was washed away during the washing of pulp, following the extraction process. Some of the xylan might have also been converted to degradation products such as furfural, carboxylic acids and humins $[33,34]$.

Table 2. Properties of aqueous hydrolysates produced by hot water extraction of bleached (BBK) and unbleached birch kraft (UBK) pulp in a flow-through system (flow rate $400 \mathrm{~mL} / \mathrm{min}$ ).

\begin{tabular}{cccc}
\hline & BBK240.2 & BBK240.10 & UBK240.10 \\
\hline Temperature, ${ }^{\circ} \mathrm{C}$ & 240 & 240 & 240 \\
Time, min & 2 & 10 & 10 \\
Xylose, $\%$ on dry pulp & 9.5 & 15.1 & 17.4 \\
Other sugars, \% on dry pulp & 0.2 & 0.4 & 0.2 \\
Mw, kDa & 2.0 & 1.8 & 10.0 \\
Polydispersity index & 1.6 & 1.4 & 3.7 \\
\hline
\end{tabular}

In addition to higher xylose yields, the hot water extraction of unbleached pulp also resulted in the recovery of xylan compounds with higher molar mass (Table 2). The average weight molar mass (Mw) of the xylan from bleached pulp was only about $2 \mathrm{kDa}$, while the Mw of the xylan from unbleached pulp was about $10 \mathrm{kDa}$; the latter $\mathrm{Mw}$ value was in agreement with our previous studies [29,35]. The lower molar mass of the xylan obtained from bleached pulp was probably due to the partial degradation of this carbohydrate fraction during the pulp bleaching operations. In terms of applications, the lower 
molar mass xylan ( $2 \mathrm{kDa}$ ) may be used for conversion to xylitol or as xylo-oligosaccharides [23]. On the other hand, the relatively high molar mass xylan extracted from unbleached pulp may be used in biodegradable composite films [36,37], or alternatively as a multifunctional food ingredient [38].

\subsection{Preparation and Quality of CNF}

The bleached kraft pulp and the water-extracted pulps were subjected to TEMPO-mediated oxidation to increase their anionic charge and thus facilitate the fibrillation process. Increasing the amount of $\mathrm{NaClO}$ in the reaction system during TEMPO oxidation increases the anionic charge of the pulp, but also decreases the DP of cellulose [13]. Since the viscosity (and molar mass) of the water-extracted pulps was rather low (see Table 1), the amount of $\mathrm{NaClO}$ added was limited to $2.5 \mathrm{mmol}$ per $\mathrm{g}$ of pulp to avoid extensive depolymerization of the cellulose chains. With this dose of $\mathrm{NaClO}$, the target anionic charge was about $0.8 \mathrm{mmol}$ per $\mathrm{g}$ of pulp, which is typically deemed sufficient for effective fibrillation. As shown in Table 3, the anionic charge of the pulp BBK240.2 after TEMPO oxidation was only $0.5 \mathrm{mmol}$ per $\mathrm{g}$, but the charge of the bleached kraft pulp and the other water-extracted pulps was about $0.7-0.8 \mathrm{mmol}$ per $\mathrm{g}$, close to the target value. The reason for the lower anionic charge in the pulp BBK240.2 is not known. As expected, the viscosity of the pulps (and thus the DP of cellulose) dropped after TEMPO oxidation, but the drop was more significant in those pulps that had a higher initial viscosity (Table 3). It should be noted, however, that the viscosity of the TEMPO-oxidized pulps is nonetheless approximate. Additional oxidation of the pulps with $\mathrm{NaClO}_{2}$ should be performed to convert small amounts of aldehydes to carboxyl groups, as the presence of aldehyde groups in the TEMPO-oxidized cellulose results in lower anionic charge, causing somewhat lower viscosity values [13].

Table 3. Anionic charge and intrinsic viscosity of bleached kraft pulp (BBK) and hot water extracted pulps after 2,2,6,6-tetramethylpiperidine-1-oxyl radical (TEMPO) oxidation.

\begin{tabular}{lcccc}
\hline & BBK & BBK240.2 & BBK240.10 & UBK240.10 \\
\hline Anionic charge, $\mathrm{mmol} / \mathrm{g}$ & 0.7 & 0.5 & 0.8 & 0.7 \\
Intrinsic viscosity, $\mathrm{mL} / \mathrm{g}$ & 176 & 139 & 85 & 122 \\
\hline
\end{tabular}

After the TEMPO-mediated oxidation, the cellulosic pulps were fibrillated in a high-pressure microfluidizer. The resulting CNF had a viscous gel-like appearance, although the CNF dispersions from the water-extracted pulps were clearly thinner (i.e., less viscous) than the CNF from the original kraft pulp (Figure 1). Moreover, the presence of residual lignin in the unbleached (UBK) pulp gave a yellowish colour to the corresponding CNF sample. AFM images showed that the cellulose fibrils in the CNF dispersions were mostly in the nanometre range and formed an interconnected fibrillar network, although some fibril aggregates could be observed regardless of the chemical composition of the pulp (Figure 2). The roughness (RMS) values, measured from a $5 \times 5 \mu \mathrm{m}^{2}$ area, were 5.5, 4.7, 5.8, and $4.7 \mathrm{~nm}$ for the CNF made from the pulps BBK, BBK240.2, BBK240.10 and UBK240.10, respectively. Overall, the nanostructural features of the CNF samples in this study were similar to those reported in the literature for TEMPO-oxidized CNF [39].

In addition to nanofibrils, SEM images revealed that considerable amounts of fibre fragments in the micrometre range were still present in the CNF dispersions (Figure 3). The number of fragments in the $\mathrm{CNF}$ obtained from the original kraft pulp appeared to be the lowest, but their dimensions were the largest, with some fragments measuring up to $14 \mu \mathrm{m}$ in cross-section and 300-400 $\mu \mathrm{m}$ in length (Figure 3a). The fibre fragments in the CNF obtained from water-extracted pulps were roughly about $2.5 \mu \mathrm{m}$ in cross-section and 10-15 $\mu \mathrm{m}$ in length, although particles up to $100 \mu \mathrm{m}$ in length were not uncommon. The higher amount of microfibers in the CNF from water-extracted pulps, and particularly in the CNF from the bleached BBK240.10 sample (Figure 3c), appears to indicate that these pulps exhibited a lower fibrillation tendency, possibly caused by their lower xylan content and consequently by stronger aggregation of cellulose fibrils [14,15]. 


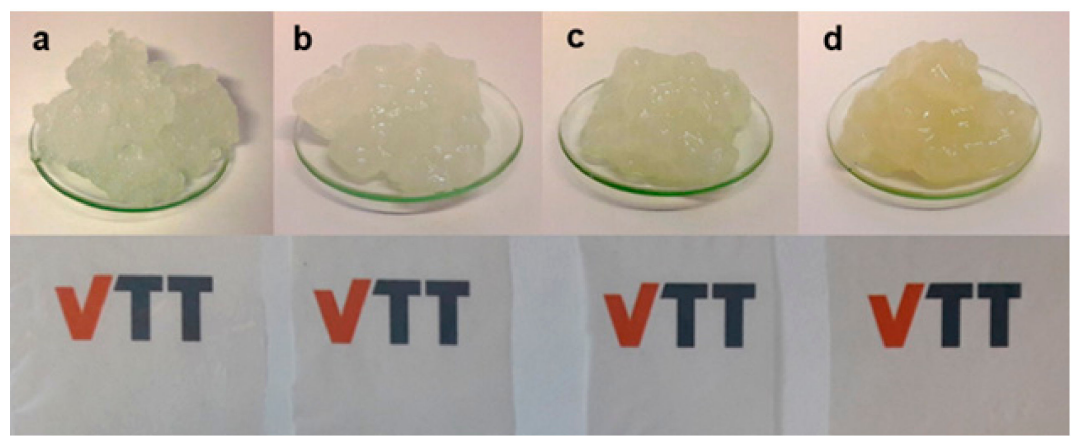

Figure 1. TEMPO-oxidized cellulose nanofibrils (CNF) and corresponding films for: (a) bleached birch kraft pulp (BBK); (b) bleached kraft pulp extracted with water at $240{ }^{\circ} \mathrm{C}$ for $2 \mathrm{~min}$ (BBK240.2); (c) bleached kraft pulp extracted with water at $240{ }^{\circ} \mathrm{C}$ for $10 \mathrm{~min}$ (BBK240.10); (d) unbleached kraft pulp extracted with water at $240^{\circ} \mathrm{C}$ for $10 \mathrm{~min}$ (UBK240.10).
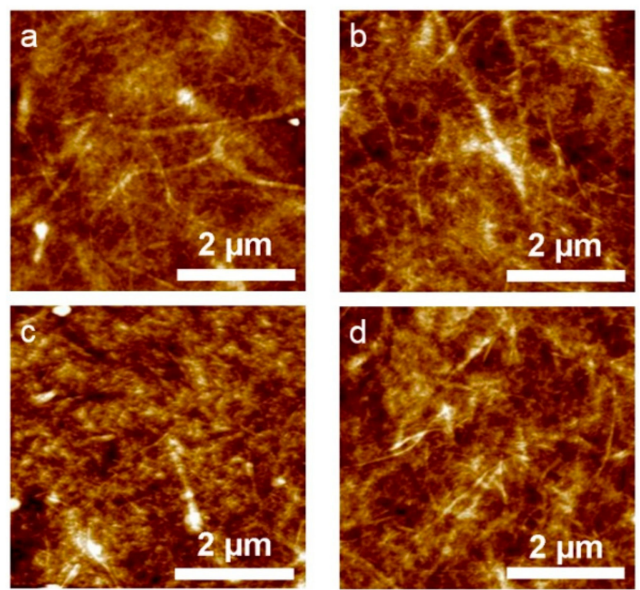

Figure 2. Atomic force microscope (AFM) height micrographs $\left(5 \times 5 \mu \mathrm{m}^{2}\right)$ of CNF samples obtained after TEMPO oxidation and microfluidization of: (a) bleached birch kraft pulp (BBK); (b) bleached kraft pulp extracted with water at $240{ }^{\circ} \mathrm{C}$ for $2 \mathrm{~min}$ (BBK240.2); (c) bleached kraft pulp extracted with water at $240{ }^{\circ} \mathrm{C}$ for $10 \mathrm{~min}$ (BBK240.10); (d) unbleached kraft pulp extracted with water at $240{ }^{\circ} \mathrm{C}$ for $10 \mathrm{~min}$ (UBK240.10).
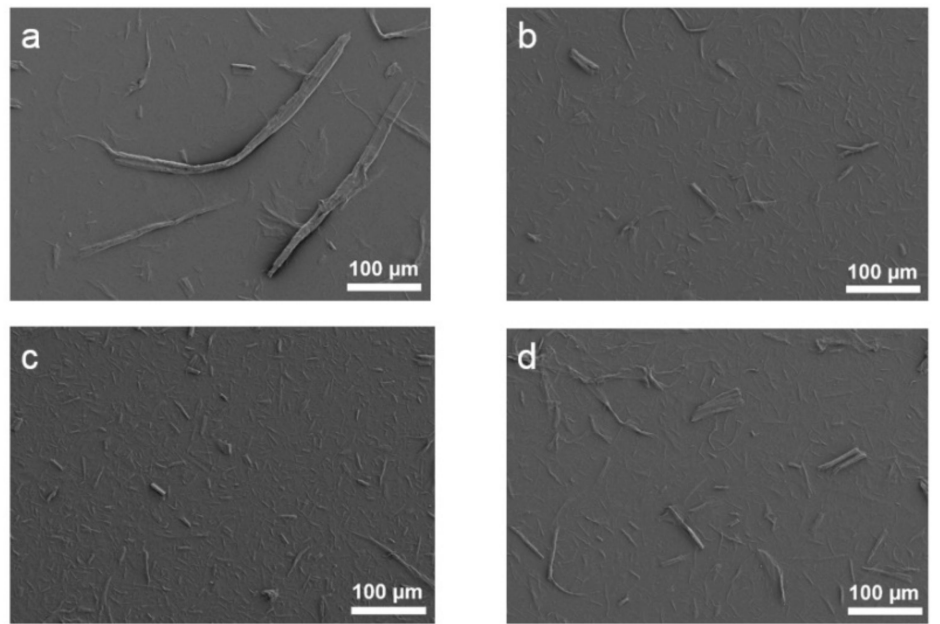

Figure 3. SEM micrographs of CNF samples obtained after TEMPO oxidation and microfluidization of: (a) bleached birch kraft pulp (BBK); (b) bleached kraft pulp extracted with water at $240{ }^{\circ} \mathrm{C}$ for 2 min (BBK240.2); (c) bleached kraft pulp extracted with water at $240{ }^{\circ} \mathrm{C}$ for $10 \mathrm{~min}$ (BBK240.10); (d) unbleached kraft pulp extracted with water at $240{ }^{\circ} \mathrm{C}$ for $10 \mathrm{~min}$ (UBK240.10). 


\subsection{Properties of the CNF Films}

Films from the four CNF samples were produced by casting the dispersions on a plastic substrate. At first, the films were produced without addition of plasticizer, but after drying overnight at room conditions the films were fully wrinkled (not shown), which not only complicates the determination of mechanical properties but also hinders their utilization in the final end-product. Therefore, a second set of films was produced after addition of $30 \%$ sorbitol to the CNF dispersions, and the new films were smooth and transparent (Figure 1). The use of sorbitol in the manufacture of CNF films in large scale has been reported earlier [40]. The mechanical properties of the films were clearly affected by the hot water extraction, as the tensile strength and ductility (strain at failure) of the films made from water-extracted bleached pulps were lower than those of the film made from the original bleached kraft (BBK) pulp (Table 4). The hot water extraction, however, did not have an effect on the stiffness of the films, which remained at a similar level ( 4 GPa). Interestingly, both BBK240.2 and BBK240.10 films had rather similar mechanical properties, despite their different xylan content. The strength and stiffness of the BBK film were lower than those reported in the literature for films made from TEMPO-oxidized nanocelluloses, but the ductility was considerably higher [41,42]. Such effect could be attributed to the addition of sorbitol as plasticizer in this study. The presence of lignin in the UBK240.10 film also had a plasticizing effect on the mechanical performance, as both the strength and the stiffness decreased and the ductility increased compared to the BBK240.10 film (Table 4). Representative stress-strain curves for all films are shown in Figure 4.

Table 4. Properties of CNF films produced from bleached (BBK) and unbleached birch kraft (UBK) pulp after hot water extraction in a flow-through system (flow rate $400 \mathrm{~mL} / \mathrm{min}$ ).

\begin{tabular}{ccccc}
\hline & BBK & BBK240.2 & BBK240.10 & UBK240.10 \\
\hline Thickness, $\mu \mathrm{m}$ & $31 \pm 1$ & $24 \pm 1$ & $21 \pm 0$ & $24 \pm 0$ \\
Tensile strength, $\mathrm{MPa}$ & $111 \pm 9$ & $87 \pm 16$ & $79 \pm 8$ & $68 \pm 3$ \\
Young's modulus, GPa & $4 \pm 0$ & $4 \pm 1$ & $4 \pm 0$ & $3 \pm 0$ \\
Ductility, \% & $11 \pm 2$ & $8 \pm 2$ & $9 \pm 1$ & $12 \pm 1$ \\
$\begin{array}{c}\text { Oxygen permeability }{ }^{1}, \\
\mathrm{cc} \times \mu \mathrm{m} / \mathrm{m}^{2} \times \text { day } \times \mathrm{kPa}\end{array}$ & $72 \pm 1$ & $66 \pm 1$ & $67 \pm 2$ & $87 \pm 3$ \\
$\begin{array}{c}\text { Water vapour permeability }{ }^{2}, \\
\mathrm{~kg} \times \mu \mathrm{m} / \mathrm{m}^{2} \times \text { day } \times \mathrm{kPa}\end{array}$ & $15 \pm 0$ & $13 \pm 1$ & $11 \pm 0$ & $13 \pm 1$ \\
\hline
\end{tabular}

${ }^{1}$ Determined at $23{ }^{\circ} \mathrm{C}$ and $80 \% \mathrm{RH} ;{ }^{2}$ determined at $23{ }^{\circ} \mathrm{C}$ and $100 / 50 \%$ RH gradient.

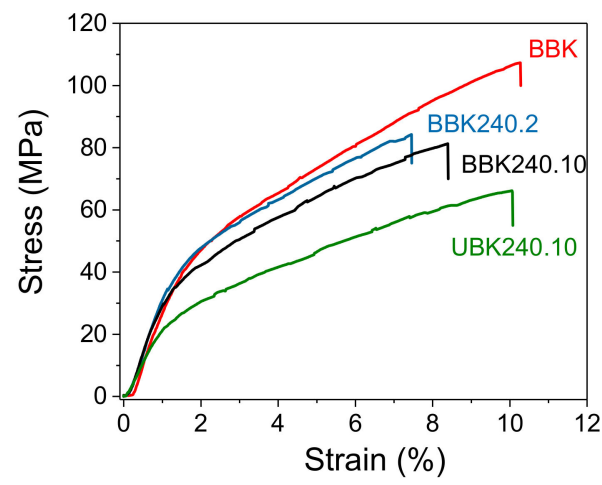

Figure 4. Representative stress-strain curves of films made from TEMPO-oxidized CNF. Sample names are the same as in Figures 1-3.

Films for food packaging should have not only good mechanical properties but also outstanding barrier properties against oxygen and water vapour to avoid spoiling of the food. The oxygen barrier properties are dependent on the RH of the environment, and thus were here measured in dry and in high $(80 \%)$ RH conditions. In dry conditions, all the films acted as an excellent barrier to oxygen, with 
permeability values lower than $0.01 \mathrm{cc} \times \mu \mathrm{m} / \mathrm{m}^{2} \times$ day $\times \mathrm{kPa}$ (not shown). At $80 \% \mathrm{RH}$, the oxygen permeability increased up to $66-87 \mathrm{cc} \times \mu \mathrm{m} / \mathrm{m}^{2} \times$ day $\times \mathrm{kPa}$ (Table 4 ). The oxygen barrier properties of the CNF films were somewhat improved by using water-extracted bleached pulps, while the presence of lignin in the films slightly increased the oxygen permeability. In all cases, the oxygen permeability was an order of magnitude lower than in the case of polyethylene [43], a common petroleum-based plastic used in food packaging. Therefore, the results of this study further confirm that CNF films have outstanding oxygen barrier properties, possibly derived from the crystalline structure of the cellulose fibrils and from the formation of dense fibrillary networks with unconnected pores, which hinder gas transfer across the material $[3,19]$.

One of the main drawbacks in films produced from lignocellulosic materials is their hydrophilicity, which typically results in poor water barrier properties. As shown in Table 4, the water vapour permeability of CNF films was decreased by using water-extracted pulps. The best performance was achieved by the BBK240.10 film, in which the permeability to moisture was decreased about $25 \%$. This improved performance may be due to the removal of hygroscopic hemicelluloses during the hot water extraction, and the consequent decrease in the amount of free hydroxyl groups. Nonetheless, it should be noted that the moisture (and oxygen) barrier properties of the films might not be directly comparable owing to some differences in film thickness. The vapour permeability values shown in Table 4 were slightly higher than those obtained earlier [44] for CNF films from bleached birch kraft pulp. However, in the aforementioned study, a mechanical pre-treatment prior to fibrillation was applied instead of TEMPO-mediated oxidation, and the number of passes also differed, which could have had an effect on the formation of fibrillar networks and the availability of water sorption sites in the CNF and in their corresponding films.

In addition to the vapour barrier properties, the hygroscopicity of the films was measured in a DVS apparatus during a full sorption (adsorption followed by desorption) cycle. Typical of lignocellulosic materials, all the CNF films showed a hysteresis in their hygroscopic behaviour, in which the moisture content at a given $\mathrm{RH}$ was higher during the desorption than during the adsorption process (Figure 5). The results also showed that all the CNF films had a similar hygroscopicity at RH below $60 \%$. Above this RH level, the films from water-extracted bleached pulps were slightly more hydrophobic, while the film from water-extracted unbleached pulp showed a similar hygroscopicity as the CNF film made from the original bleached kraft pulp. The slightly higher hygroscopicity of the UBK240.10 film, compared to the BBK240.10 film with a similar xylan content, may be due to the presence of free hydroxyls in the lignin structure.

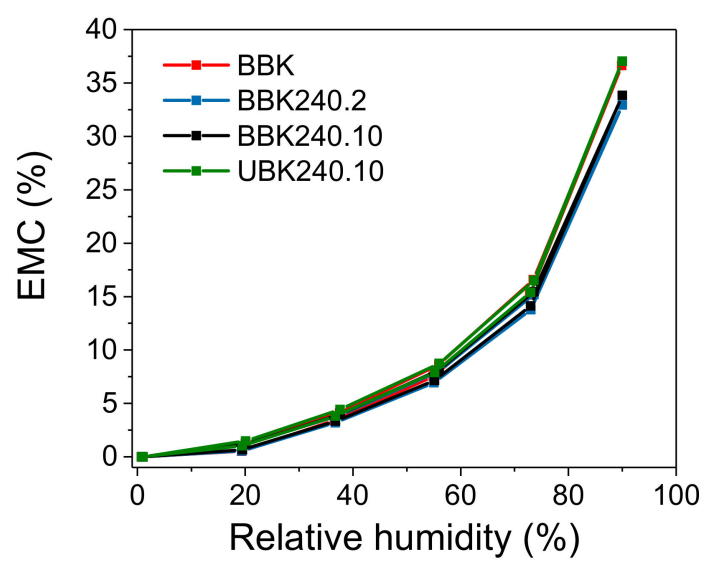

Figure 5. Equilibrium moisture content (EMC) of CNF films as a function of RH in the atmosphere. Sample names are the same as in Figures 1-3. 


\section{Conclusions}

Hot water extractions of kraft pulp can be applied to remove and recover the hemicelluloses prior to fibrillation of the pulp for the manufacture of CNF films. The extraction of hemicelluloses seemingly decreases the efficiency of fibrillation, as indicated by the higher number of fibre fragments in the CNF dispersions obtained by TEMPO oxidation and subsequent fluidization of the pulps. In any case, the CNF from both kraft and water-extracted pulps show an interconnected network of fibrils in the nanometre range and form smooth and transparent films after addition of sorbitol as plasticizer. The CNF films from water-extracted bleached pulps have similar stiffness but lower tensile strength than the films made from bleached kraft pulp, presumably due to the lower hemicellulosic (i.e., xylan) content. Despite the lower strength, the mechanical properties of the films should be sufficient for many food packaging applications. Moreover, the extraction of hemicelluloses from bleached pulp apparently results in CNF films with lower hydrophilicity and enhanced barrier properties to oxygen and water vapour, although films having the same thickness should be prepared in order to confirm this effect. On the other hand, the presence of lignin in the pulp (and in the CNF) leads to films with poorer mechanical and barrier properties.

Based on the results of this study, hot water extraction of bleached birch kraft pulp would be a suitable process to produce CNF films with improved barrier properties for food packaging, while obtaining a low molar mass xylan side-stream for high-value applications (e.g., prebiotics). The use of unbleached pulps would be preferable to obtain a higher molar mass xylan but would not be desirable for the manufacture of CNF films, as all properties except ductility appear to deteriorate.

Author Contributions: M.B. and H.O. were responsible for the conceptualization, investigation and data validation of this study. M.B. wrote the original draft and H.O. participated in the review and editing process.

Funding: This research was funded by the Academy of Finland through the PURCELL project (decision number 312470).

Acknowledgments: Atte Mikkelson, Panu Lahtinen, Timo Kaljunen, and Katja Pettersson from VTT Technical Research Centre of Finland Ltd. are thanked for their skilful support with SEC analyses of water-extracted pulps and aqueous hydrolysates, preparation of CNF and films, AFM imaging of CNF dispersions, and determination of mechanical and barrier properties of the films.

Conflicts of Interest: The authors declare no conflict of interest. The funders had no role in the design of the study; in the collection, analyses, or interpretation of data; in the writing of the manuscript, or in the decision to publish the results.

\section{References}

1. Klemm, D.; Kramer, F.; Moritz, S.; Lindström, T.; Ankerfors, M.; Gray, D.; Dorris, A. Nanocelluloses: A new family of nature-based materials. Angew. Chem. Int. Ed. 2011, 50, 5438-5466. [CrossRef] [PubMed]

2. Iguchi, M.; Yamanaka, S.; Budhiono, A. Bacterial cellulose-A masterpiece of nature's arts. J. Mater. Sci. 2000, 35, 261-270. [CrossRef]

3. Lavoine, N.; Desloges, I.; Dufresne, A.; Bras, J. Microfibrillated cellulose-Its barrier properties and applications in cellulosic materials: A review. Carbohydr. Polym. 2012, 90, 735-764. [CrossRef] [PubMed]

4. De France, K.J.; Hoare, T.; Cranston, E.D. Review of Hydrogels and Aerogels Containing Nanocellulose. Chem. Mater. 2017, 29, 4609-4631. [CrossRef]

5. Gomez, C.H.; Serpa, A.; Velásquez-Cock, J.; Gañán, P.; Castro, C.; Vélez, L.; Zuluaga, R.; Velasquez, J. Vegetable nanocellulose in food science: A review. Food Hydrocoll. 2016, 57, 178-186. [CrossRef]

6. Dufresne, A. Nanocellulose: A new ageless bionanomaterial. Mater. Today 2013, 16, 220-227. [CrossRef]

7. Vieira, M.G.A.; Da Silva, M.A.; Dos Santos, L.O.; Beppu, M.M. Natural-based plasticizers and biopolymer films: A review. Eur. Polym. J. 2011, 47, 254-263. [CrossRef]

8. Zimmermann, T.; Bordeanu, N.; Strub, E. Properties of nanofibrillated cellulose from different raw materials and its reinforcement potential. Carbohydr. Polym. 2010, 79, 1086-1093. [CrossRef]

9. Missoum, K.; Belgacem, M.N.; Bras, J. Nanofibrillated Cellulose Surface Modification: A Review. Materials 2013, 6, 1745-1766. [CrossRef] 
10. Spence, K.L.; Venditti, R.A.; Rojas, O.J.; Habibi, Y.; Pawlak, J.J. A comparative study of energy consumption and physical properties of microfibrillated cellulose produced by different processing methods. Cellulose 2011, 18, 1097-1111. [CrossRef]

11. Pääkko, M.; Ankerfors, M.; Kosonen, H.; Nykänen, A.; Ahola, S.; Österberg, M.; Ruokolainen, J.; Laine, J.; Larsson, P.T.; Ikkala, O.; et al. Enzymatic hydrolysis combined with mechanical shearing and high-pressure homogenization for nanoscale cellulose fibrils and strong gels. Biomacromolecules 2007, 8, 1934-1941. [CrossRef] [PubMed]

12. Abdul Khalil, H.P.S.; Davoudpour, Y.; Islam, M.N.; Mustapha, A.; Sudesh, K.; Dungani, R.; Jawaid, M. Production and modification of nanofibrillated cellulose using various mechanical processes: A review. Carbohydr. Polym. 2014, 99, 649-665. [CrossRef] [PubMed]

13. Isogai, A.; Saito, T.; Fukuzumi, H. TEMPO-oxidized cellulose nanofibers. Nanoscale 2011, 3, 71-85. [CrossRef] [PubMed]

14. Iwamoto, S.; Abe, K.; Yano, H. The effect of hemicelluloses on wood pulp nanofibrillation and nanofiber network characteristics. Biomacromolecules 2008, 9, 1022-1026. [CrossRef] [PubMed]

15. Chaker, A.; Alila, S.; Mutjé, P.; Vilar, M.R.; Boufi, S. Key role of the hemicellulose content and the cell morphology on the nanofibrillation effectiveness of cellulose pulps. Cellulose 2013, 20, 2863-2875. [CrossRef]

16. Meng, Q.; Fu, S.; Lucia, L.A. The role of heteropolysaccharides in developing oxidized cellulose nanofibrils. Carbohydr. Polym. 2016, 144, 187-195. [CrossRef] [PubMed]

17. Meng, Q.; Li, H.; Fu, S.; Lucia, L.A. The non-trivial role of native xylans on the preparation of TEMPO-oxidized cellulose nanofibrils. React. Funct. Polym. 2014, 85, 142-150. [CrossRef]

18. Tenhunen, T.M.; Peresin, M.S.; Penttilä, P.A.; Pere, J.; Serimaa, R.; Tammelin, T. Significance of xylan on the stability and water interactions of cellulosic nanofibrils. React. Funct. Polym. 2014, 85, 157-166. [CrossRef]

19. Rojo, E.; Peresin, M.S.; Sampson, W.W.; Hoeger, I.C.; Vartiainen, J.; Laine, J.; Rojas, O.J. Comprehensive elucidation of the effect of residual lignin on the physical, barrier, mechanical and surface properties of nanocellulose films. Green Chem. 2015, 17, 1853-1866. [CrossRef]

20. Ferrer, A.; Quintana, E.; Filpponen, I.; Solala, I.; Vidal, T.; Rodríguez, A.; Laine, J.; Rojas, O.J. Effect of residual lignin and heteropolysaccharides in nanofibrillar cellulose and nanopaper from wood fibers. Cellulose 2012, 19, 2179-2193. [CrossRef]

21. Pääkkönen, T.; Dimic-Misic, K.; Orelma, H.; Pönni, R.; Vuorinen, T.; Maloney, T. Effect of xylan in hardwood pulp on the reaction rate of TEMPO-mediated oxidation and the rheology of the final nanofibrillated cellulose gel. Cellulose 2016, 23, 277-293. [CrossRef]

22. Arola, S.; Malho, J.M.; Laaksonen, P.; Lille, M.; Linder, M.B. The role of hemicellulose in nanofibrillated cellulose networks. Soft Matter 2013, 9, 1319-1326. [CrossRef]

23. Deutschmann, R.; Dekker, R.F.H. From plant biomass to bio-based chemicals: Latest developments in xylan research. Biotechnol. Adv. 2012, 30, 1627-1640. [CrossRef] [PubMed]

24. Willför, S.; Sundberg, K.; Tenkanen, M.; Holmbom, B. Spruce-derived mannans-A potential raw material for hydrocolloids and novel advanced natural materials. Carbohydr. Polym. 2008, 72, 197-210. [CrossRef]

25. Laine, C.; Kemppainen, K.; Kuutti, L.; Varhimo, A.; Asikainen, S.; Grönroos, A.; Määttänen, M.; Buchert, J.; Harlin, A. Extraction of xylan from wood pulp and brewer's spent grain. Ind. Crop. Prod. 2015, 70, $231-237$. [CrossRef]

26. Hakala, T.K.; Liitiä, T.; Suurnäkki, A. Enzyme-aided alkaline extraction of oligosaccharides and polymeric xylan from hardwood kraft pulp. Carbohydr. Polym. 2013, 93, 102-108. [CrossRef]

27. Roselli, A.; Asikainen, S.; Stepan, A.; Monshizadeh, A.; Von Weymarn, N.; Kovasin, K.; Wang, Y.; Xiong, H.; Turunen, O.; Hummel, M.; et al. Comparison of pulp species in IONCELL-P: Selective hemicellulose extraction method with ionic liquids. Holzforschung 2016, 70, 291-296. [CrossRef]

28. Borrega, M.; Sixta, H. Purification of cellulosic pulp by hot water extraction. Cellulose 2013, 20, $2803-2812$. [CrossRef]

29. Borrega, M.; Concha-Carrasco, S.; Pranovich, A.; Sixta, H. Hot water treatment of hardwood kraft pulp produces high-purity cellulose and polymeric xylan. Cellulose 2017, 24, 5133-5145. [CrossRef]

30. Janson, J. Calculation of the polysaccharide composition of wood and pulp. Pap. Puu 1970, 52, 323-329.

31. Sasaki, M.; Fang, Z.; Fukushima, Y.; Adschiri, T.; Arai, K. Dissolution and hydrolysis of cellulose in subcritical and supercritical water. Ind. Eng. Chem. Res. 2000, 39, 2883-2890. [CrossRef] 
32. Zhao, X.; Zhang, L.; Liu, D. Biomass recalcitrance. Part I: The chemical compositions and physical structures affecting the enzymatic hydrolysis of lignocellulose. Biofuels Bioprod. Biorefining 2012, 6, 465-482. [CrossRef]

33. Danon, B.; Marcotullio, G.; de Jong, W. Mechanistic and kinetic aspects of pentose dehydration towards furfural in aqueous media employing homogeneous catalysis. Green Chem. 2014, 16, 39-54. [CrossRef]

34. Mittal, A.; Chatterjee, S.G.; Scott, G.M.; Amidon, T.E. Modeling xylan solubilization during autohydrolysis of sugar maple and aspen wood chips: Reaction kinetics and mass transfer. Chem. Eng. Sci. 2009, 64, 3031-3041. [CrossRef]

35. Borrega, M.; Larsson, P.T.; Ahvenainen, P.; Ceccherini, S.; Maloney, T.; Rautkari, L.; Sixta, H. Birch wood pre-hydrolysis vs. pulp post-hydrolysis for the production of xylan-based compounds and cellulose for viscose application. Carbohydr. Polym. 2018, 190, 212-221. [CrossRef] [PubMed]

36. Gordobil, O.; Egüés, I.; Urruzola, I.; Labidi, J. Xylan-cellulose films: Improvement of hydrophobicity, thermal and mechanical properties. Carbohydr. Polym. 2014, 112, 56-62. [CrossRef] [PubMed]

37. Peng, X.W.; Ren, J.L.; Zhong, L.X.; Sun, R.C. Nanocomposite films based on xylan-rich hemicelluloses and cellulose nanofibers with enhanced mechanical properties. Biomacromolecules 2011, 12, 3321-3329. [CrossRef]

38. Rosa-Sibakov, N.; Hakala, T.K.; Sözer, N.; Nordlund, E.; Poutanen, K.; Aura, A.M. Birch pulp xylan works as a food hydrocolloid in acid milk gels and is fermented slowly in vitro. Carbohydr. Polym. 2016, 154, 305-312. [CrossRef] [PubMed]

39. Hänninen, T.; Orelma, H.; Laine, J. TEMPO oxidized cellulose thin films analysed by QCM-D and AFM. Cellulose 2015, 22, 165-171. [CrossRef]

40. Tammelin, T.; Hippi, U.; Salminen, A. Method for the Preparation of Nanofibrillated Cellulose (NFC) Films on Supports. WO Patent WO 2013/060934 A3, 2013.

41. Lindström, T. Aspects on nanofibrillated cellulose (NFC) processing, rheology and NFC-film properties. Curr. Opin. Colloid In. 2017, 29, 68-75. [CrossRef]

42. Saito, T.; Kumamoto, Y.; Fukuzumi, H.; Iwata, T.; Isogai, A. Transparent and highgGas barrier films of cellulose nanofibers prepared by TEMPO-mediated oxidation. Biomacromolecules 2008, 10, 162-165. [CrossRef]

43. Zhong, Y.; Janes, D.; Zheng, Y.; Hetzer, M.; De Kee, D. Mechanical and oxygen barrier properties of organoclay-polyethylene nanocomposite films. Polym. Eng. Sci. 2007, 47, 1101-1107. [CrossRef]

44. Vartiainen, J.; Pelto, J.; Kaljunen, T.; Kenttä, E. Hydrophobization of cellophane and cellulose nanofibrils films by supercritical state carbon dioxide impregnation with walnut oil. Nord. Pulp. Pap. Res. J. 2016, 31, 541-547. [CrossRef] 